\title{
Analysis of Precursors Prior to Rock Burst in Granite Tunnel Using Acoustic Emission and Far Infrared Monitoring
}

\author{
Zhengzhao Liang, ${ }^{1,2}$ Xiangxin Liu, ${ }^{3}$ Yanbo Zhang, ${ }^{3}$ and Chunan Tang \\ ${ }^{1}$ School of Civil Engineering, Dalian University of Technology, Dalian 116024, China \\ ${ }^{2}$ The Key Laboratory of Safety for Geotechnical and Structural Engineering of Hubei Province, \\ Wuhan University, Wuhan 430072, China \\ ${ }^{3}$ College of Mining Engineering, Hebei United University, Tangshan, Hebei 063009, China \\ Correspondence should be addressed to Zhengzhao Liang; z.z.liang@163.com
}

Received 9 October 2013; Accepted 5 November 2013

Academic Editor: Xiao-Wei Ye

Copyright (C) 2013 Zhengzhao Liang et al. This is an open access article distributed under the Creative Commons Attribution License, which permits unrestricted use, distribution, and reproduction in any medium, provided the original work is properly cited.

\begin{abstract}
To understand the physical mechanism of the anomalous behaviors observed prior to rock burst, the acoustic emission (AE) and far infrared (FIR) techniques were applied to monitor the progressive failure of a rock tunnel model subjected to biaxial stresses. Images of fracturing process, temperature changes of the tunnel, and spatiotemporal serials of acoustic emission were simultaneously recorded during deformation of the model. The $b$-value derived from the amplitude distribution data of AE was calculated to predict the tunnel rock burst. The results showed that the vertical stress enhanced the stability of the tunnel, and the tunnels with higher confining pressure demonstrated a more abrupt and strong rock burst. Abnormal temperature changes around the wall were observed prior to the rock burst of the tunnel. Analysis of the AE events showed that a sudden drop and then a quiet period could be considered as the precursors to forecast the rock burst hazard. Statistical analysis indicated that rock fragment spalling occurred earlier than the abnormal temperature changes, and the abnormal temperature occurred earlier than the descent of the AE $b$-value. The analysis indicated that the temperature changes were more sensitive than the AE $b$-value changes to predict the tunnel rock bursts.
\end{abstract}

\section{Introduction}

The study of rock failure under stress is a subject of widespread interest, with relevance to both rock engineering applications, such as tunneling design, oil recovery, safe design of nuclear waste repositories, and natural processes such as volcanism and seismology. As a typical failure style, a rock burst is a kind of sudden expulsion of rock occurring under high stress in deep underground engineering. The opening of a tunnel relieves neighboring rocks of tremendous pressure, which can literally cause the rock to explode as it attempts to reestablish stress and strain equilibrium. The released energy leads to the violent fracture of the surrounding rock around the excavation and reduces the potential energy of the rock, which makes the surrounding rock to reach another equilibrium state.
In the past few years, many methods of forecasting rock bursts have been proposed, including rock mechanics assessment, stress detection, and modern mathematical theories. However, a comprehensive understanding of rock bursts and associated damage mechanisms has remained elusive $[1,2]$. Fairhurst and Cook considered stress-induced buckling of rock layers as a rock burst mechanism, but most researchers have limited this mechanism to fairly minor events [3]. White et al. described field examples of large rock bursts and other rib deformation that they inferred to have resulted from buckling [4]. The evidence for one large burst described as caused by buckling, the Craig drift rock burst (Strathcona Mine of Falconbridge, Ltd., ON, Canada) is suggestive but not compelling. Many studies simply sidestep consideration of damage mechanisms or ascribe damage to a seismic impulse or to crushing, with no specific damage mechanism specified. 
For many reasons, it is important to be able to predict the time, location, and intensity of potential rock burst. Rock fracture and rock burst in stressed rock have been observed in the laboratory by a number of methods. One approach is the direct observation of samples by scanning electron microscopy (SEM) [5], optical camera, and microscopy [6]. These images provide direct and visual description of fracturing process in a straightforward way.

Far infrared (FIR) is a region in the infrared spectrum of electromagnetic radiation. When temperature changes, the related infrared energy is proportional to the fourth power of the absolute temperature. Small temperature change will cause large variations in infrared energy. Far infrared (FIR) technology is often applied to monitor temperature variations of stressed rocks $[7,8]$. Based on a series of experimental studies, Geng and Cui pointed out that rock IR radiation energy increased with increasing stress on the rock and that some IR precursor information could predict rock fracturing $[9,10]$. Based on the pioneering IR experimental studies on mine rocks, $\mathrm{Wu}$ and Wang suggested that there existed three kinds of IR radiation temperature features and three kinds of IR thermal features during the loading and failure process of coal and sandstone; they also found that the precursor indication through IR detection was comparable to that of acoustic emission detection and electrical resistance detection [11-13].

Far infrared monitoring can capture temperature distribution near the surface of the specimens. The far infrared results can reflect the amount of stress induced energy conducted from inside the specimens, but the deep energy and temperature condition cannot be obtained. These direct observations, including video monitoring and far infrared monitoring, are useful techniques for both brittle and ductile failure but is limited in that only the surface of the test specimen can be observed [14].

Another approach involves monitoring the hypocenter distribution, energy released, and hit counts of acoustic emission (AE) events caused by microcracking activity [1416]. AE technique provides an analysis of the microcracking activity inside the rock volume and has an important advantage over other techniques in that tests can be performed under confining pressure, which is very important in the simulation of underground conditions. AE are considered very useful for understanding and explaining the various mechanisms of unstable failure of rock, that is, rock burst problems. Experiments aimed at investigating failure zone development and fault growth under loading conditions, that is, when failure is allowed to develop unstably, have become possible and also more significant in recent years. The disadvantage of the $\mathrm{AE}$ technique is that it is insensitive to ductile deformation, which does not produce appreciable AE. However, rock bursts in brittle failure can produce intensive $\mathrm{AE}$ activities and large amounts of energy, because almost all rock bursts occur in rocks with high stiffness and strength in high stress condition. The AE technique is applicable to locate the failure positions and determine the energy released in rock failure laboratory experiments and engineering applications related to slope failure and excavation problems in mines [17-20]. The recent development of high-speed multichannel waveform recording technology has made it possible to monitor the hypocenters of $\mathrm{AE}$ associated with spontaneously/unstably fracturing processes in stressed rock samples with high precision.

Among various parameters analyzed from AE data, the most significant one is the $b$-value which is derived from the amplitude distribution data of AE following the methods used in rock burst prediction as well as seismology investigations. Variations in the seismic $b$-value have already been qualitatively linked to the state of stress, to changes in fracture mechanism in laboratory-scale rock fracture experiments, and to the heterogeneity of the material $[7,16,20]$.

Rock bursts basically depend on the size and depth of the excavation. The likelihood of rock bursts occurring increases as depth increases. This study presents the rock burst investigation of a granite tunnel subjected to different confining pressures by using acoustic emission (AE) and far infrared (FIR) techniques to monitor the precursory information. The characteristics of the AE and FIR were analyzed to predict rock burst hazard.

\section{Experiment Investigation}

2.1. Specimen Preparation and Loading Condition. Totally, 12 granite rock specimens were prepared to model the rock burst of underground tunnels. The dimension of the specimens was approximately $150 \mathrm{~mm} \times 150 \mathrm{~mm} \times 75 \mathrm{~mm}$, and an opening (30 $\mathrm{mm}$ diameter) was prepared in the center of the specimens (Figure 1). To reduce boundary effects, the side length of the specimens was 5 times that of the diameter of the opening. Biaxial loading was applied on the specimens to model the tunnel in different stress conditions. The horizontal force was increased to $30 \mathrm{KN}, 60 \mathrm{KN}$, or $90 \mathrm{KN}$ and then remained to be a constant. The vertical displacement loading was increased gradually until the collapse of the specimens with a rate of $0.3 \mathrm{~mm}$ per minute. All the experimental cases and the loading conditions were listed in Table 1.

The compression tests were carried out on a servocontrolled rock testing machine (RLW-3000), and the deformation and the vertical force applied were monitored. The acoustic emission activities were recorded by an AE detector with 8 channels. The multiparameter AE data, including AE hits, ring-down counts, and amplitudes, was obtained using a computer-based AE system (PAC). The thermal condition of the specimens was monitored by a far infrared radiation imager (ThermaCAM SC3000). A high speed video with high resolution was stationed in front of the rock testing machine to record the progressive failure process of the granite specimens.

To consider the influence of lateral stress on the deformation of the rocks, another group of specimens was subjected to uniaxial compression beforehand. Their force-time curves under uniaxial compression were shown in Figure 2. It was observed that all the specimens were in elastic deformation stage when the axial force was increased to $90 \mathrm{KN}$. Therefore, in the following tests, the maximal lateral force was limited to $90 \mathrm{KN}$. 
TABle 1: Specimens dimension and loading condition.

\begin{tabular}{|c|c|c|c|}
\hline No. & Lateral force $(\mathrm{kN})$ & Vertical displacement loading $(\mathrm{mm} / \mathrm{min})$ & Dimension $(\mathrm{mm})$ \\
\hline HSHG-30-1 & \multirow{4}{*}{30} & \multirow{4}{*}{0.3} & $149.22 \times 72.06 \times 150.94$ \\
\hline HSHG-30-2 & & & $147.76 \times 75.96 \times 149.22$ \\
\hline HSHG-30-3 & & & $151.68 \times 72.84 \times 153.12$ \\
\hline HSHG-30-4 & & & $150.32 \times 75.16 \times 151.12$ \\
\hline HSHG-60-1 & \multirow{4}{*}{60} & \multirow{4}{*}{0.3} & $149.12 \times 74.58 \times 148.76$ \\
\hline HSHG-60-2 & & & $151.20 \times 73.86 \times 152.94$ \\
\hline HSHG-60-3 & & & $149.92 \times 74.94 \times 151.66$ \\
\hline HSHG-60-4 & & & $150.24 \times 75.18 \times 150.36$ \\
\hline HSHG-90-1 & \multirow{4}{*}{90} & \multirow{4}{*}{0.3} & $149.40 \times 74.52 \times 148.92$ \\
\hline HSHG-90-2 & & & $148.34 \times 73.48 \times 149.42$ \\
\hline HSHG-90-3 & & & $148.40 \times 75.32 \times 149.16$ \\
\hline HSHG-90-4 & & & $149.82 \times 74.84 \times 150.26$ \\
\hline
\end{tabular}

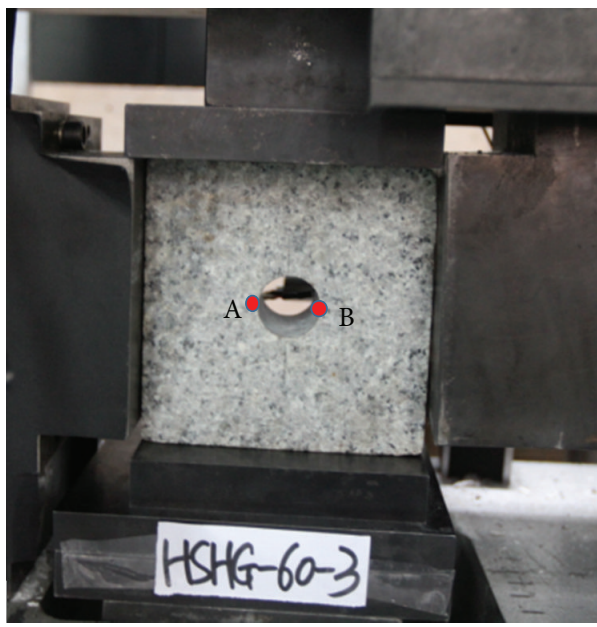

(a)

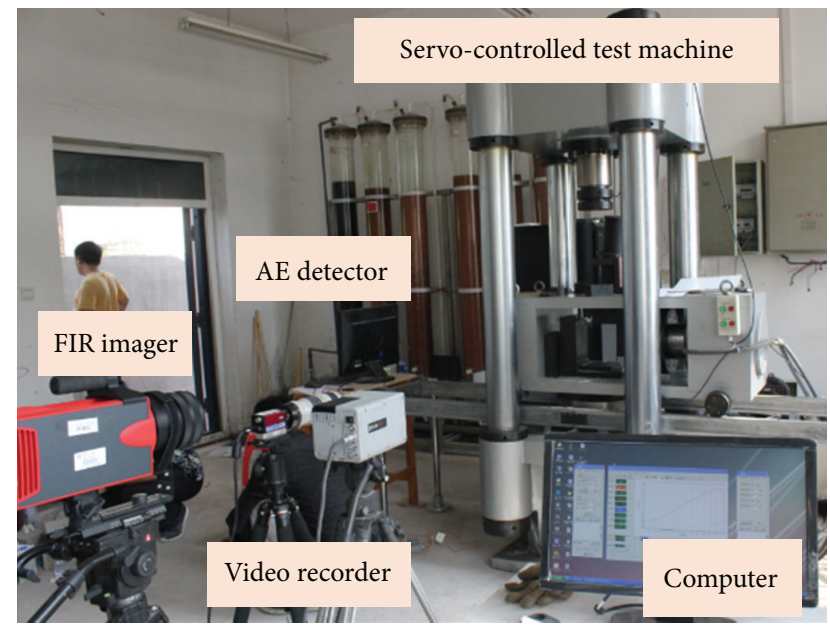

(b)

FIGURE 1: The servo-controlled rock test machine (RLW-3000).

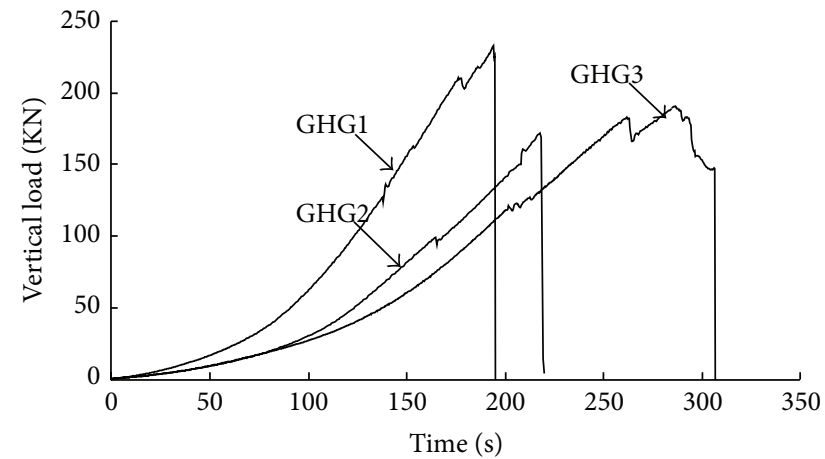

FIGURE 2: Vertical load-time curves of the granite specimens under uniaxial compression.

2.2. Fracturing Images. The macroscopic fracture pictures of the granite tunnel specimens under different lateral pressure were shown in Figure 3. It is noted that the specimens were named HSHG-XX-Y, where XX indicated the lateral force, and $Y$ was the number in that group.

For the specimens under the horizontal force of $30 \mathrm{KN}$, only a few small rock fragments were observed to fall down from the right side wall of the tunnel at $825 \mathrm{~s}$, and larger flakes of rocks were spalled on the surface of the tunnel wall at 910 s. Macrofractures initiated from the two sides and then propagated to the boundary at $940 \mathrm{~s}$, which resulted in the bulking of the rock tunnel (Figure 3(a)).

Figure 3(b) demonstrated the fracture patterns of the specimen HSHG-60-2. A few rock fragments appeared at $838 \mathrm{~s}$, and some small fragments were observed to eject from the sides of the tunnel at $961 \mathrm{~s}$. The specimen fractured in the same mode with HSHG-30-2 when the macrofractures appeared.

The intensive rock burst appeared in the specimen HSHG-90-2. When the horizontal force was increased to 

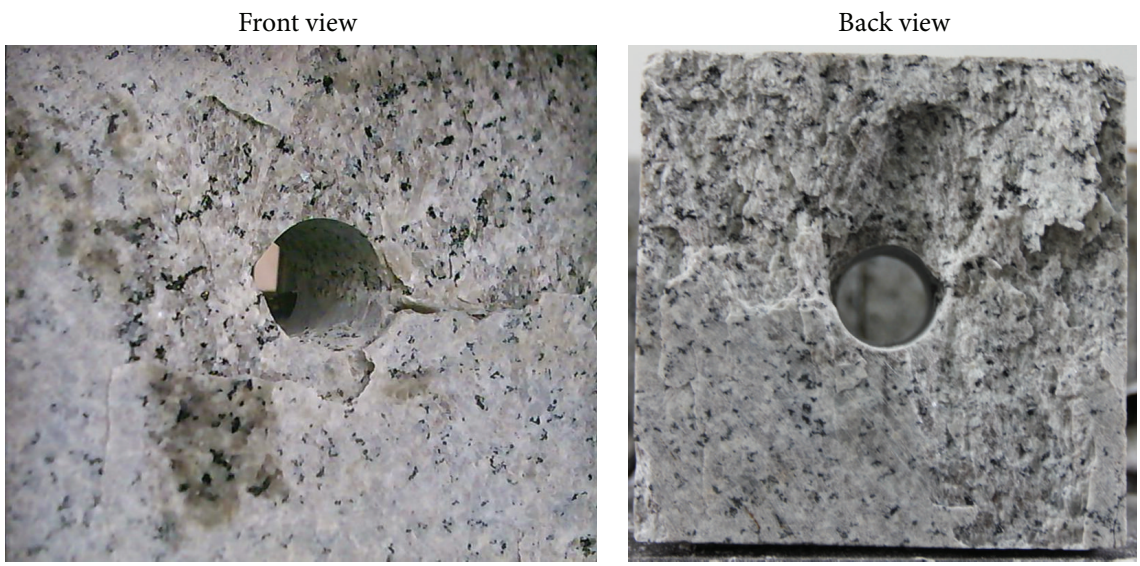

(a) HSHG-30-1
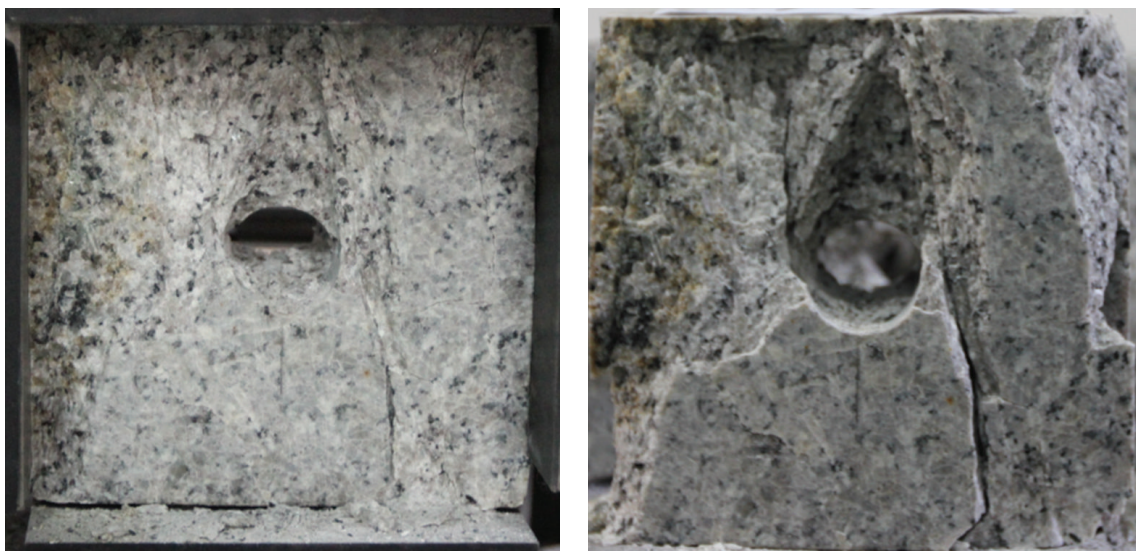

(b) HSHG-60-2
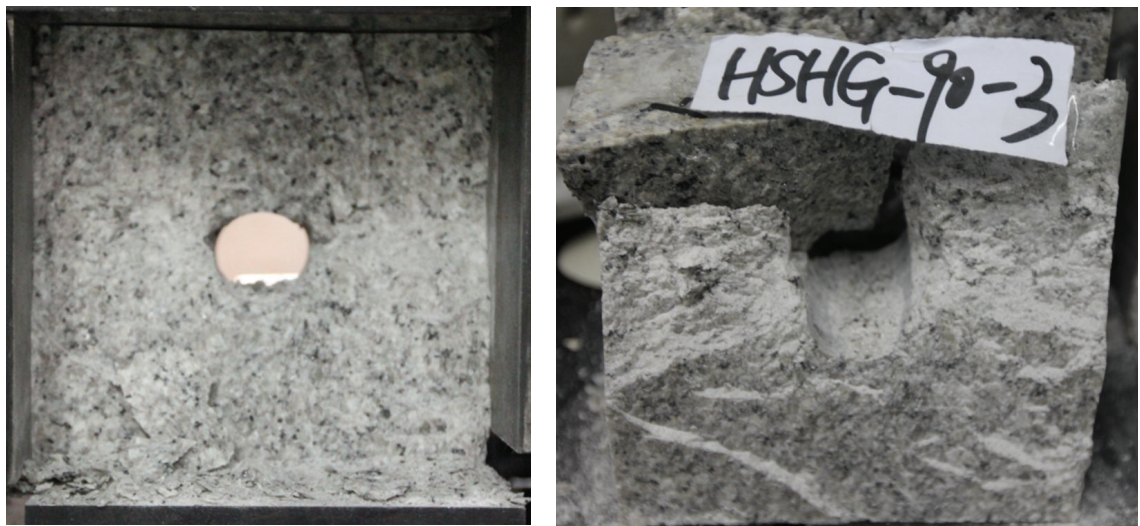

(c) HSHG-90-3

FIGURE 3: The macroscopic fracture pictures of the granite specimens.

$90 \mathrm{KN}$, rock spalling did not appear until 909 s. The specimen collapsed abruptly only in several seconds when the explosion of rock fragments was observed. Due to the high vertical stress and dilatation of the rock, the cross section of the tunnel was compressed to be an ellipse shape.

2.3. Far Infrared Thermal Results. The far infrared thermal imager can monitor high temperature or low temperature on the surface of the specimens. Only the high temperature of Point A and Point B (Figure 1) was recorded to analyse the rock burst precursors. Because the compressive stress concentrating around the tunnel wall and the friction between the microcracks produced energy release, the high temperature was much useful to predict the hazard.

The vertical force versus time curves and the temperature of Point A and B on two sides of the wall versus time 


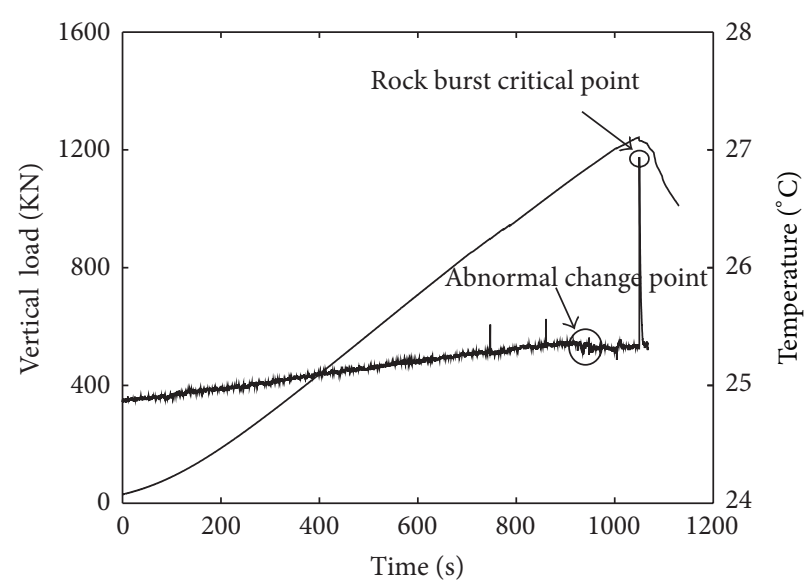

(a) HSHG-30-1

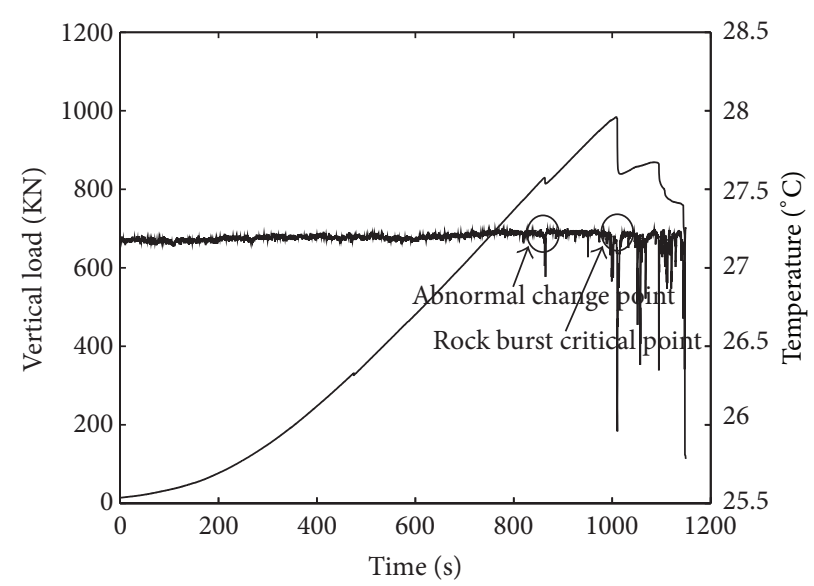

(b) HSHG-60-3

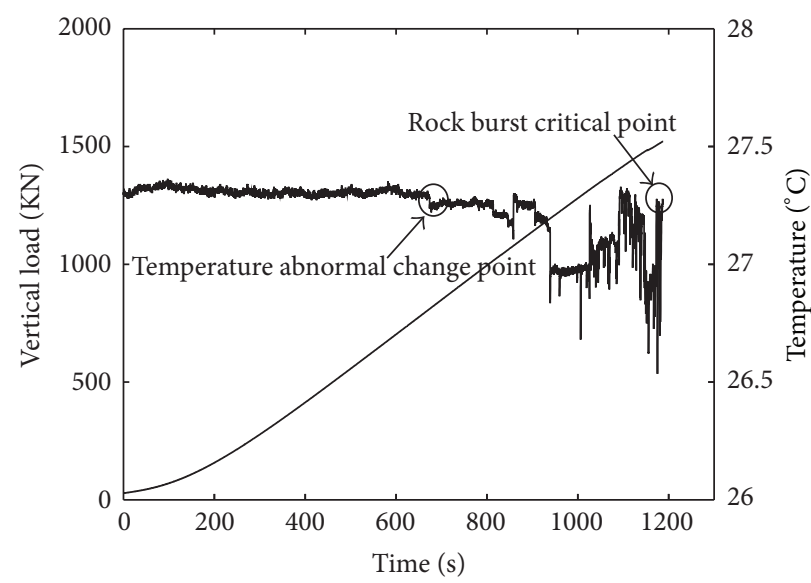

(c) HSHG-90-2

FIGURE 4: The relation of the temperature, vertical load, and loading time of the granite specimens under different lateral pressures.

curves were plotted in Figure 4. It was observed that the average temperature of Point $\mathrm{A}$ and Point $\mathrm{B}$ increased as the vertical stress increased. The drops of the force-time curves resulted in the temperature fluctuations. When the stress was increased gradually prior to the tunnel failure, the temperature had many sudden jumps and drops. The fluctuation of the temperature suggested the events of stress concentration or stress release. The tensile fracturing led to the temperature drops, whereas the compressive stress or the friction between the crack walls led to the temperature jumps.

The temperature had an obvious great jump prior to the rock burst point, which could be termed as rock burst critical point. How to capture this critical point becomes much significant for prediction of rock bursts in tunnel engineering.

It is interesting that the range of temperature variation for the specimen HSHG-30-1 was smaller than the specimens HSHG-60-3 and HSHG-90-2 due to the variation of the lateral stress. The compressive stress was much smaller in the specimen HSHG-30-1 than in the specimens HSHG-60-3 and HSHG-90-2. Similarly, compared with the specimen HSHG$60-3$, the variation of the temperature was more violent for the specimen HSHG-90-2.
2.4. Acoustic Emission Results. Figure 5 shows the vertical force and $\mathrm{AE}$ rate versus the loading time curves for the granite tunnel specimens under different vertical stress. The AE activities during the whole loading process could be divided into four stages: the increasing stage, the active stage, the decreasing stage, and the burst stage. In the first stage, $\mathrm{AE}$ rate was increased gradually with the increasing of the vertical stress, resulting from the opening or closing of the microcracks existing in the rocks. Initiation, propagation, and coalescence of new cracks led to AE increasing in the active stage. The curves of all the specimens underwent a downward period. The AE rate was decreased gradually even though the vertical stress was increased continuously in this stage. Only a small number of AE events were observed at the end of the decreasing stage. The accumulated elastic energy in the placid period caused the rock burst finally. In the last period, the weakened rock tunnel could not contain such great amount of energy applied by the loading system, and the release of the potential energy made the surrounding rock to reach another equilibrium state, accompanied by a sharp vertical force drop.

Rocks undergoing brittle failure produce a large number of acoustic emissions of varying amplitudes due to the formation and growth of microcracks, tensile cracks, shear cracks, 


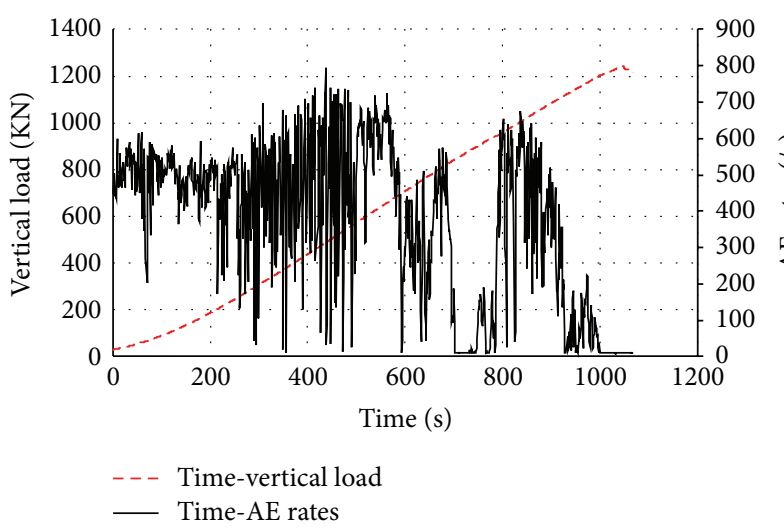

(a) HSHG-30-2

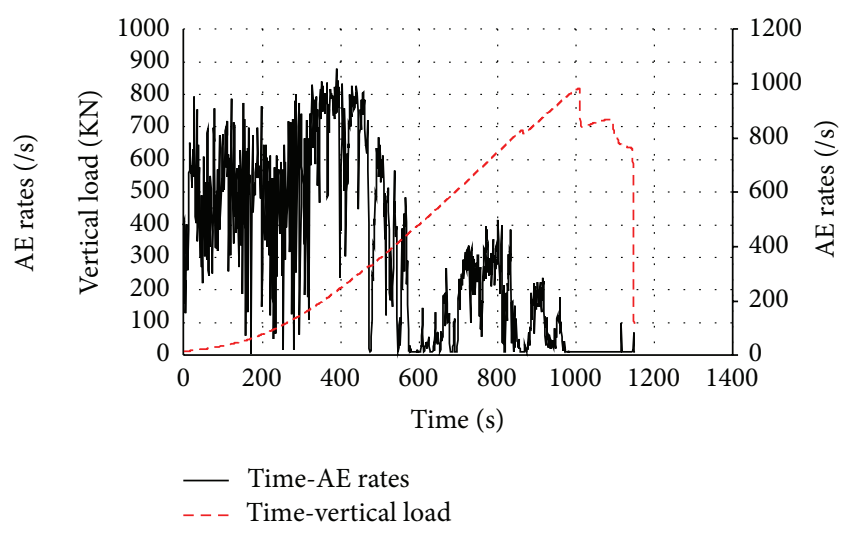

(b) HSHG-60-1

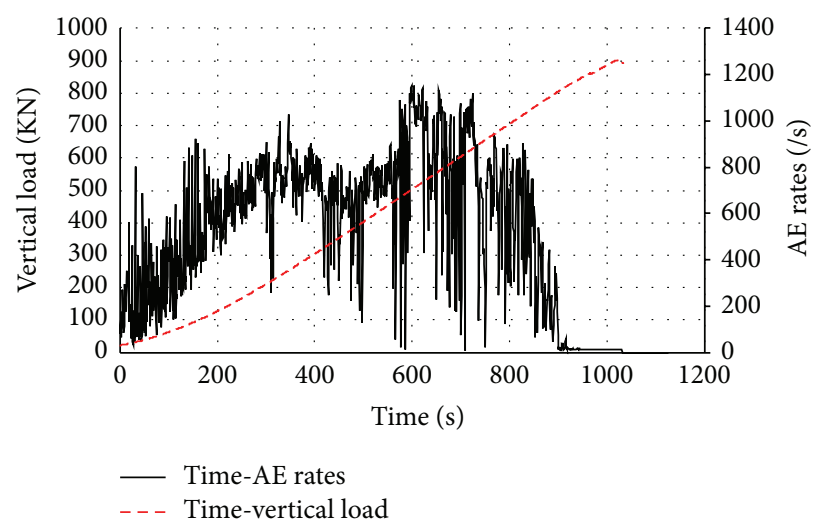

(c) HSHG-90-2

FIGURE 5: The curves of the vertical force and AE rate versus the loading time for the granite tunnel specimens.

and so forth. The cumulative as well as the discrete frequencyamplitude distribution of such $\mathrm{AE}$ shows a descending gradient and a major portion of it is linear. The amplitude data of that linear range is used to compute the $b$-value (slope of the log-linear frequency-magnitude distribution of AE) following the Gutenberg-Richter relationship for the cumulative frequency distribution data [21]. The GutenbergRichter Law in the most common form reads as follows:

$$
\log [N(M)]=a-b M,
$$

where $N$ is the number of events with magnitude larger than $M$.

$M$ and $a$ and $b$ are two constant coefficients.

Relation (1) has been widely researched and applied to study the effect of the magnitude uncertainty on the $b$ value and the effect of various regionalization on the $b$-value $[22,23]$. In this investigation, the relation of accumulative frequency of $\mathrm{AE}$ events and the magnitude of $\mathrm{AE}$ energy was calculated to obtain the $b$-value by G-R law.

There are good prospects for making a quantitative diagnosis of the fracture development in the test rock structure under stress on the basis of AE amplitude information in terms of $b$-value. However, the method used for the determination of $b$-value is important, since selection of the amplitude or magnitude limits of the "linear range" of the cumulative frequency distribution data of $\mathrm{AE}$ is critical. In the present study, the data of low amplitude or magnitude were included to calculate the $b$-value.

Figure 6 plots the curves of the vertical force and the $b$ value of $\mathrm{AE}$ events versus the loading time for the granite tunnel specimens. It was observed that the $b$-value fluctuated in a limited range at a high level in the beginning loading stage, indicating stress concentration, stress transfer, or stress release in the tunnel model, whereas the associated initiation and propagation of the microcracks in the specimens did not cause macrofracturing. The $\mathrm{AE}$ events generated due to the closure and rubbing of preexisting microcracks in the rock began to show a high $b$-value in this stage.

The $b$-value demonstrated a descendent gradient when the rock burst critical point was approaching. This phenomenon could be observed in all the rock specimens. The continuous descent of the $b$-value could be considered as the precursors to predict the tunnel rock bursts. Here the point where the $b$-value began to decrease was assumed to be the critical point.

The high $b$-value arose due to a large number of small $\mathrm{AE}$ hits (or events) representing new crack formation and slow crack growth, whereas the low $b$-value indicated faster or unstable crack growth accompanied by relatively high 


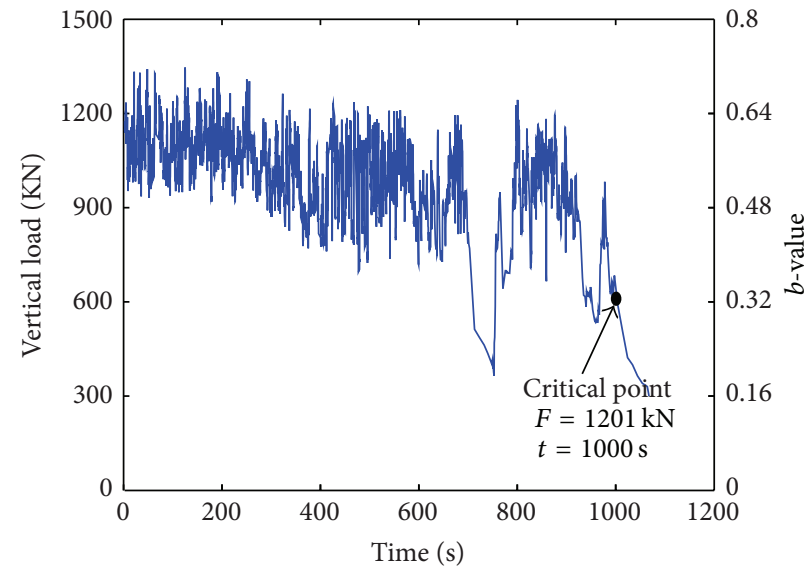

(a) HSHG-30-1

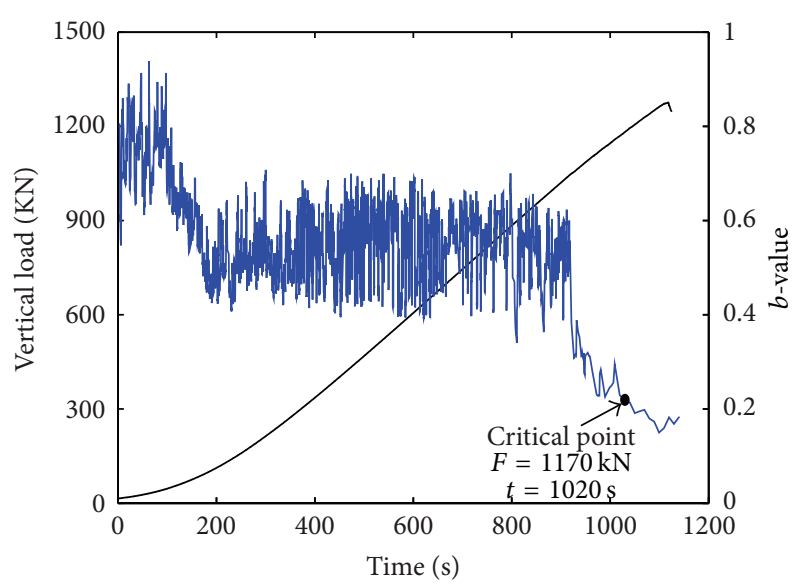

(b) HSHG-60-1

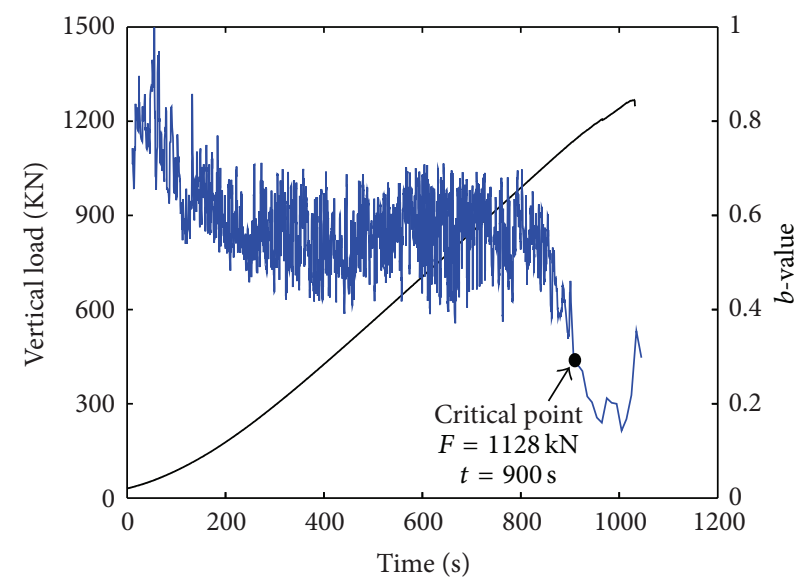

(c) HSHG-90-2

FIGURE 6: The curves of the vertical load and the $b$-value of AE energy versus the loading time for the granite tunnel specimens.

TABLE 2: Statistical analysis of the critical time and vertical peak load time.

\begin{tabular}{|c|c|c|c|c|c|c|c|c|c|}
\hline$F_{H}(\mathrm{KN})$ & Specimen no. & $F_{\max }(\mathrm{kN})$ & $t_{\max }(\mathrm{s})$ & $F_{b}(\mathrm{kN})$ & $t_{b}(\mathrm{~s})$ & $F_{b} / F_{\max }(\%)$ & $\begin{array}{c}\text { Average } \\
F_{b} / F_{\max }(\%)\end{array}$ & $t_{b} / t_{\max }(\%)$ & $\begin{array}{c}\text { Average } \\
t_{b} / t_{\max }(\%)\end{array}$ \\
\hline \multirow{2}{*}{30} & HSHG-30-1 & 1242 & 1048.7 & 1201 & 997.9 & 96.7 & \multirow{2}{*}{97.5} & 95.2 & \multirow{2}{*}{96.7} \\
\hline & HSHG-30-2 & 1241.5 & 947.5 & 1220 & 930.6 & 98.3 & & 98.2 & \\
\hline \multirow{2}{*}{60} & HSHG-60-1 & 1275.8 & 1118.2 & 1170 & 1019.9 & 91.7 & \multirow{2}{*}{95.8} & 91.2 & \multirow{2}{*}{95.3} \\
\hline & HSHG-60-3 & 1287 & 1107.4 & 1285 & 1099.8 & 99.8 & & 99.3 & \\
\hline \multirow{2}{*}{90} & HSHG-90-1 & 1521 & 1188 & 1415 & 1098.7 & 93 & \multirow{2}{*}{91.0} & 92.5 & \multirow{2}{*}{89.9} \\
\hline & HSHG-90-2 & 1267.2 & 1030.7 & 1128 & 900 & 89 & & 87.3 & \\
\hline
\end{tabular}

$F_{b}$ : vertical load at the critical point of the $b$-value.

$t_{b}$ : time at the critical point of the $b$-value.

$F_{\text {max }}$ : vertical peak load.

$t_{\max }$ : time at the peak load point.

$F_{H}$ : lateral load (horizontal load).

amplitude $\mathrm{AE}$ in large numbers, which resulted in the impending rock burst of the tunnel model.

Table 2 listed the peak vertical load, the load at the critical point on the $b$-value curves, and their times (HSHG-301, HSHG-30-2, HSHG-60-1, HSHG-60-3, HSHG-90-1, and HSHG-90-2). To make a comparison, the vertical peak load and the peak time for all the specimens were listed. The average ratio of the vertical load at the critical point to the peak load $\left(F_{b} / F_{\max }\right)$ and the average ratio of the critical time to the peak load time $\left(t_{b} / t_{\max }\right)$ were calculated. It could be found that the average $F_{b} / F_{\max }$ was decreased from $97.5 \%$ to $91.0 \%$, and the average $t_{b} / t_{\max }$ was decreased from $96.7 \%$ to 
89.9\% when the horizontal load was increased from $30 \mathrm{KN}$ to $90 \mathrm{KN}$.

\section{Discussion}

3.1. The $b$-Value. The fluctuation of the $b$-value indicated the progressive fracture and damage process of the rock tunnel specimens under biaxial compression. The results show that, during the early loading stages, a large number of AE events generated from the closure and rubbing of the preexisting microcracks made a high $b$-value. Then the formation and propagation of new cracks on the eventual fracture plane produced a large amount of energy and AE hits, resulting in the high $b$-value. In the elastic deformation stage, the $b$-value curves showed a decreasing trend due to a small number of AE events. The $b$-value decreased sharply due to the crack coalescence and the accompanying stress relief under the further increased stress. The critical time of this decreasing phenomenon can be considered as most useful for prediction of rock burst time. These observations have some important applications for monitoring the stability and integrity of rock tunnels.

3.2. The Alarm Time of the Tunnel Rock Burst. The anomalies recorded by all kinds of sensors are often used to predict earthquakes, slope failure, or rock burst. The abnormal variation of seismic events are often analyzed to predict earthquakes, and anomalous microseismic changes often appear prior to slope failure or rock burst in rock engineering. The abnormal variation of the results monitored by $\mathrm{AE}$ and FIR can also provide the precursory information to predict the rock burst time of the tunnel model.

One of the most difficult problems of rock burst forecasting is time prediction. However, time prediction requires a better understanding of the processes which take place in rocks. Unlike earthquakes, the laboratory experiments can provide many monitoring techniques to capture the occurrence of abnormal behaviors of the small rock specimens.

The alarm time predicted by FIR technique was earlier than the time predicted by AE technique. The alarm time of the critical point monitored by FIR and $\mathrm{AE}$ techniques and the peak loading point were listed in Table 3. We used the critical time to alarm the rock burst hazards. In far infrared monitoring, the critical point was defined as the appearance of the abnormal temperature changes prior to the rock bursts. In acoustic emission monitoring, the critical point was defined as the point where the $b$-value of the frequency-magnitude distribution of $\mathrm{AE}$ began to descend sharply. As shown in Table 3, the alarm time predicted by far infrared radiation monitoring was earlier than that by acoustic emission monitoring for all the specimens. It indicated that the temperature changes were more sensitive than those of acoustic emission. The local temperature is increased when the stresses concentrated, whereas the acoustic emissions only can be located when the stresses are increased to failure occurrence subsequently. Therefore, the abnormal changes of the acoustic emission is later than those of the temperature.
TABLE 3: The alarm time of rock bursts analyzed from the AE and FIR results.

\begin{tabular}{cccc}
\hline \multirow{2}{*}{$F_{H}$} & \multirow{2}{*}{ Specimen no. } & \multicolumn{2}{c}{ Alarm time (s) } \\
& & FIR & AE \\
\hline \multirow{2}{*}{30} & HSHG-30-1 & 923 & 999 \\
& HSHG-30-2 & 875 & 905 \\
\hline \multirow{2}{*}{60} & HSHG-60-1 & 879 & 1009 \\
& HSHG-60-3 & 788 & 785 \\
\hline \multirow{2}{*}{90} & HSHG-90-1 & 674 & 924 \\
& HSHG-90-2 & 878 & 856 \\
\hline
\end{tabular}

The AE technique seems to be the most useful monitoring technique in rock tunnels. Due to rock's opaque feature, it is difficult to monitor the deformation and failure in rocks by using camera or video monitoring. What is more, compared with soil, rocks have less deformation before failure because of their high stiffness, which makes the deformation of rocks much smaller than soil. Similar to video monitoring, FIR technique only records the temperature variations of rock surfaces. Neither of them can detect the internal failure of analyzing the seismic sources, released energy, and associated amplitude and counts in rocks.

3.3. The Rock Burst Prediction Method. A combined prediction method based on multiparameters by multimonitoring techniques will provide a more useful and accurate early alarm [24, 25]. The video monitoring can capture some phenomena of rock fragment spalling, ejection, or rock explosion, the far infrared radiation technique can monitor the temperature variation on the surface of rocks, and the AE technique provides the seismic event counts, energy release, and failure location information. Each technique has its own advantages. The combined prediction method based on the high speed video, the far infrared and AE technique will provide a more accurate rock burst alarm. The block scheme of rock burst prediction algorithm is shown in Figure 7. The first criterion is whether the phenomenon of rock fragment fall down, ejection or rock explosion can be observed. The second criterion is the appearance of abnormal temperature changes monitored by the FIR technique. The last criterion is the descent of $b$-value based on AE data analysis. The alarm should be cancelled if all the criteria are not satisfied. Otherwise, these abnormal variations can be considered as precursors of a potential rock burst hazard in the rock tunnel, and some supporting measures should be carried out to strengthen the tunnels.

\section{Conclusions}

The acoustic emission and far infrared techniques and video monitoring were applied to monitor the failure precursors of a rock tunnel model subjected to biaxial compressive stress. The images of the fracturing process, temperature variation of the tunnel, and the spatiotemporal serials of the acoustic emission were obtained. The precursors of the monitored data by AE and FIR were analyzed. A combined 


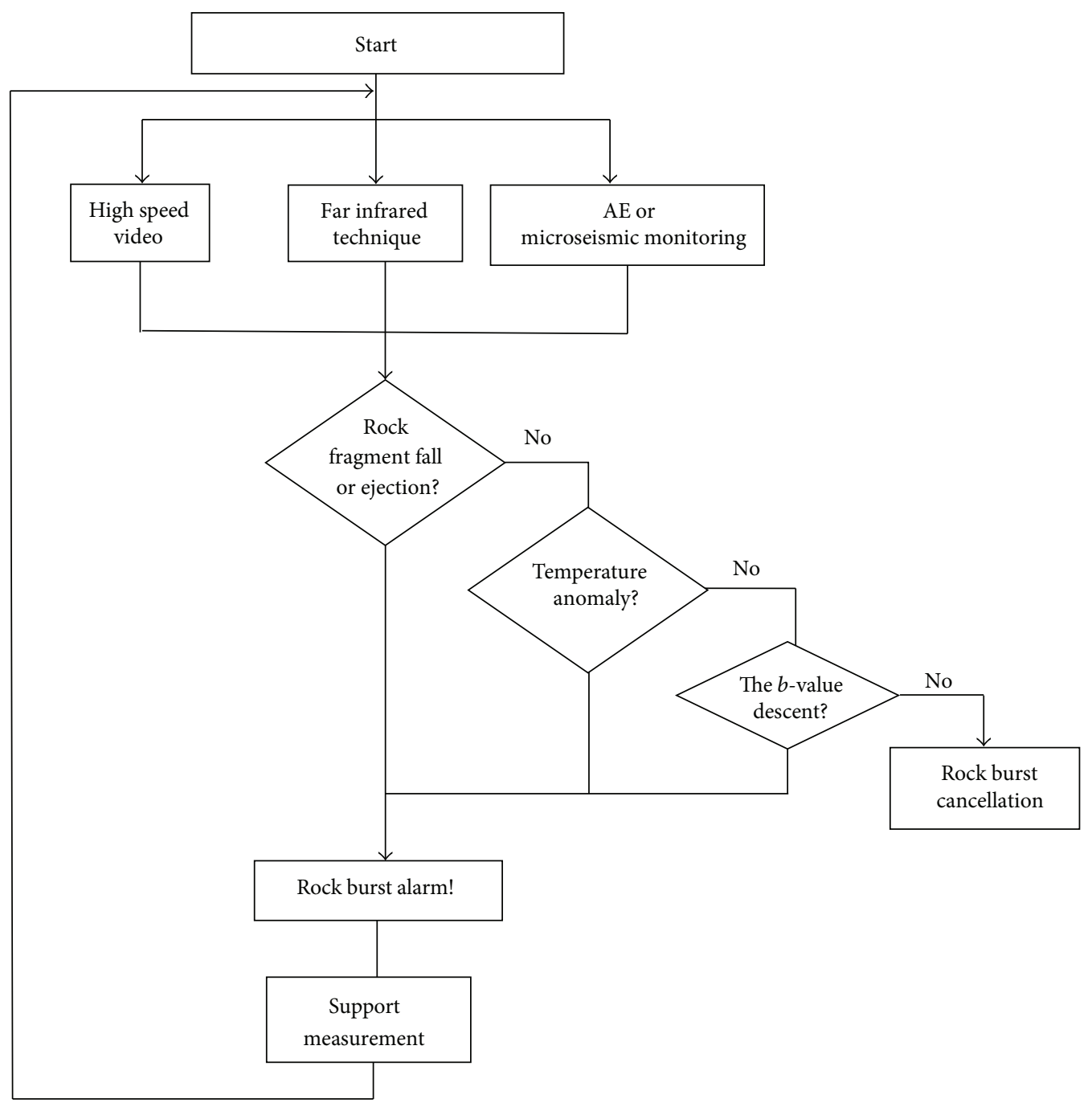

FIGURE 7: The block scheme of rock burst prediction algorithm.

rock burst prediction method based on acoustic emission and far infrared radiation was proposed to analyze rock burst hazards in tunneling engineering. The following conclusions can be drawn.

(1) The vertical pressure can enhance the stability of the tunnel model and delay the approach of rock burst hazards. However, the tunnel with higher confining pressure demonstrated a more abrupt and stronger rock burst.

(2) Rock fragment spalling and abnormal temperature around the wall were observed before the collapse of the tunnel.

(3) The analysis of the AE events showed that a sudden drop and then a quiet period could be considered as the precursors of the rock burst hazard.

(4) The abnormal temperature appeared earlier than the descent of the AE $b$-value. The analysis indicated that the temperature variations was more sensitive than the $\mathrm{AE} b$-value variations to predict rock bursts.

\section{Acknowledgments}

This work was supported by the National Program on Key Basic Research Project of China (973 Program) (Grant no. 2014CB047100), the National Natural Science Foundation of China (Grant nos. 51121005, 51079017, and 51274053), the Foundation for the Author of National Excellent Doctoral Dissertation of China (no. 200960), the Open Research Fund Program of the Key Laboratory of Safety for Geotechnical and Structural Engineering of Hubei Province, and the Fundamental Research Funds for the Central Universities in China (DUT12ZD102).

\section{References}

[1] C. A. Tang, "Preliminary engineering application of microseismic monitoring technique to rockburst prediction in tunneling of Jinping II project," Journal of Rock Mechanics and Geotechnical Engineering, vol. 2, no. 3, pp. 193-208, 2010.

[2] N. W. Xu, C. A. Tang, L. C. Li et al., "Microseismic monitoring and stability analysis of the left bank slope in Jinping first 
stage hydropower station in southwestern China," International Journal of Rock Mechanics and Mining Sciences, vol. 48, no. 6, pp. 950-963, 2011.

[3] C. Fairhurst and N. G. W. Cook, "The phenomenon of rock splitting parallel to the direction of maximum compression in the neighborhood of a surface," in Proceedings of the 1st Congress on the International Society of Rock Mechanics, vol. 1, pp. 687-692, National Laboratory of Civil Engineering, Lisbon, Portugal, 1966.

[4] B. G. White, J. K. Whyatt, and D. F. Scott, "Geologic factors in rock bursts in the coeur d'alene mining district: structure," in Proceedings: Mechanics and Mitigation of Violent Failure in Coal and Hard-Rock Mines, H. Maleki, P. F. Wopat, R. C. Repsher, and R. J. Tuchman, Eds., pp. 217-230, US Bureau of Mines Special Publication, 1995.

[5] Y. Zhao, "Crack pattern evolution and a fractal damage constitutive model for rock," International Journal of Rock Mechanics and Mining Sciences, vol. 35, no. 3, pp. 349-366, 1998.

[6] S. J. D. Cox and C. H. Scholz, "Rupture initiation in shear fracture of rocks: an experimental study," Journal of Geophysical Research, vol. 93, no. 4, pp. 3307-3320, 1988.

[7] V. Frid, "Electromagnetic radiation method water-infusion control in rockburst-prone strata," Journal of Applied Geophysics, vol. 43, no. 1, pp. 5-13, 2000.

[8] V. Frid, "Calculation of electromagnetic radiation criterion for rockburts hazard forecast in coal mines," Pure and Applied Geophysics, vol. 158, no. 5-6, pp. 931-944, 2001.

[9] N.-G. Geng, C.-Y. Cui, and M.-D. Deng, "The remote sensing observation in experiments of rock failure and the beginning of remote sensing rock mechanics," Acta Seismologica Sinica, vol. 14, pp. 645-652, 1992.

[10] C. Y. Cui, M. D. Deng, and N. G. Geng, "Rock spectral signatures under different pressures," Chinese Science Bulletin, vol. 38, no. 16, pp. 1377-1382, 1993.

[11] L. X. Wu and J. Z. Wang, "Study on the thermal infrared radiation temperature omen in coal-measure rock yielding underground pressure," China Mining Magazine, vol. 6, no. 6, pp. 42-48, 1997.

[12] L. X. Wu and J. Z. Wang, "Features of infrared thermal image and radiation temperature of coal rocks loaded," Science in China D, vol. 41, no. 2, pp. 158-164, 1998.

[13] L. X. Wu and J. Z. Wang, "Infrared radiation features of coal and rocks under loading," International Journal of Rock Mechanics and Mining Sciences, vol. 35, no. 7, pp. 969-976, 1998.

[14] X. Lei, K. Masuda, O. Nishizawa et al., "Detailed analysis of acoustic emission activity during catastrophic fracture of faults in rock," Journal of Structural Geology, vol. 26, no. 2, pp. 247258, 2004.

[15] D. A. Lockner, J. D. Byerlee, V. Kuksenko, A. Ponomarev, and A. Sidorin, "Quasi-static fault growth and shear fracture energy in granite," Nature, vol. 350, no. 6313, pp. 39-42, 1991.

[16] K. Mogi, Earthquake Prediction, Academic Press, London, UK, 1985.

[17] M. Cai and P. K. Kaiser, "Assessment of excavation damaged zone using a micromechanics model," Tunnelling and Underground Space Technology, vol. 20, no. 4, pp. 301-310, 2005.

[18] N. Dixon and M. Spriggs, "Quantification of slope displacement rates using acoustic emission monitoring," Canadian Geotechnical Journal, vol. 44, no. 8, pp. 966-976, 2007.

[19] D. Arosio, L. Longoni, M. Papini, M. Scaioni, L. Zanzi, and M. Alba, "Towards rockfall forecasting through observing deformations and listening to microseismic emissions," Natural Hazards and Earth System Science, vol. 9, no. 4, pp. 1119-1131, 2009.

[20] P. G. Meredith, I. G. Main, and C. Jones, "Temporal variations in seismicity during quasi-static and dynamic rock failure," Tectonophysics, vol. 175, no. 1-3, pp. 249-268, 1990.

[21] B. Gutenberg and C. F. Richter, Seismicity of the Earth and Associated Phenomena, Princeton University Press, Princeton, NJ, USA, 1954.

[22] W. D. Smith, "The $b$-value as an earthquake precursor," Nature, vol. 289, no. 5794, pp. 136-139, 1981.

[23] M. V. M. S. Rao, D. S. N. Murthy, G. M. Nagaraja Rao, S. K. Mohanty, and S. Udayakumar, "Stress-induced micro-cracking and brittle failure of Godhra granite, Gujarat: a laboratory investigation using acoustic emission," Journal of the Geological Society of India, vol. 64, no. 6, pp. 775-783, 2004.

[24] T.-H. Yi, H.-N. Li, and M. Gu, "Recent research and applications of GPS-based monitoring technology for high-rise structures," Structural Control and Health Monitoring, vol. 20, no. 5, pp. 649670, 2013.

[25] T.-H. Yi, H.-N. Li, and M. Gu, "Optimal sensor placement for structural health monitoring based on multiple optimization strategies," The Structural Design of Tall and Special Buildings, vol. 20, no. 7, pp. 881-900, 2011. 


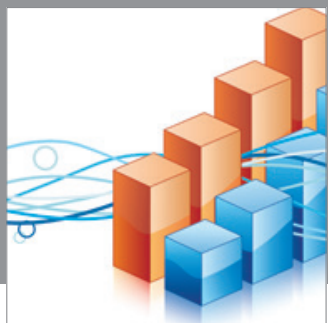

Advances in

Operations Research

mansans

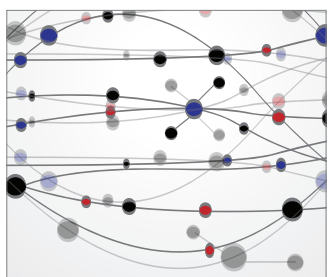

The Scientific World Journal
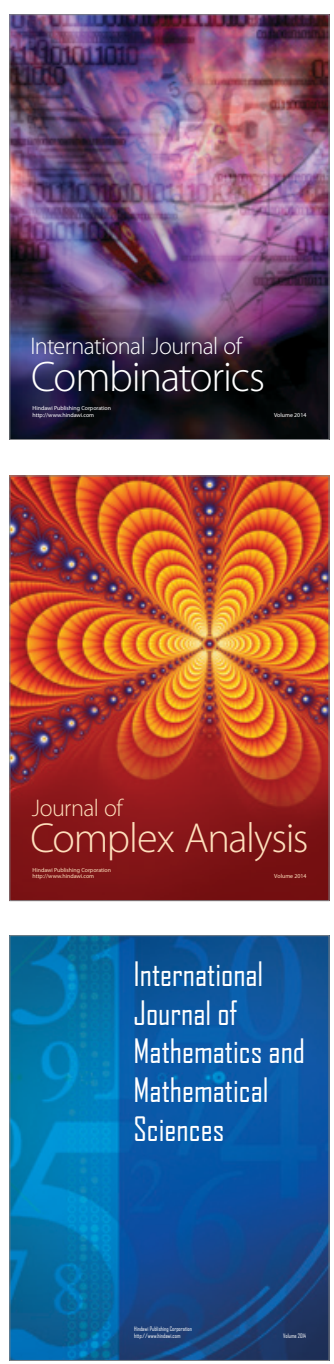
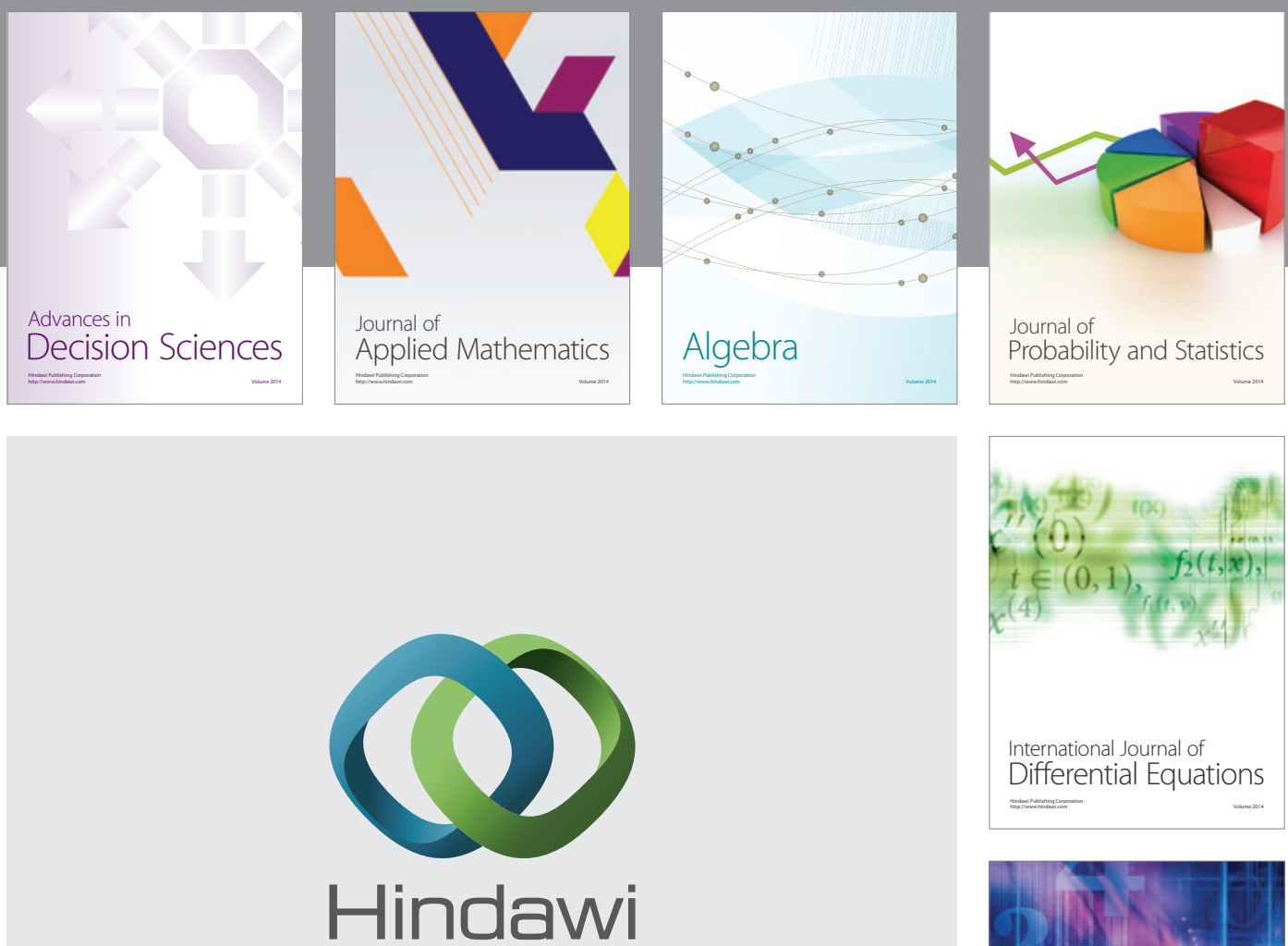

Submit your manuscripts at http://www.hindawi.com
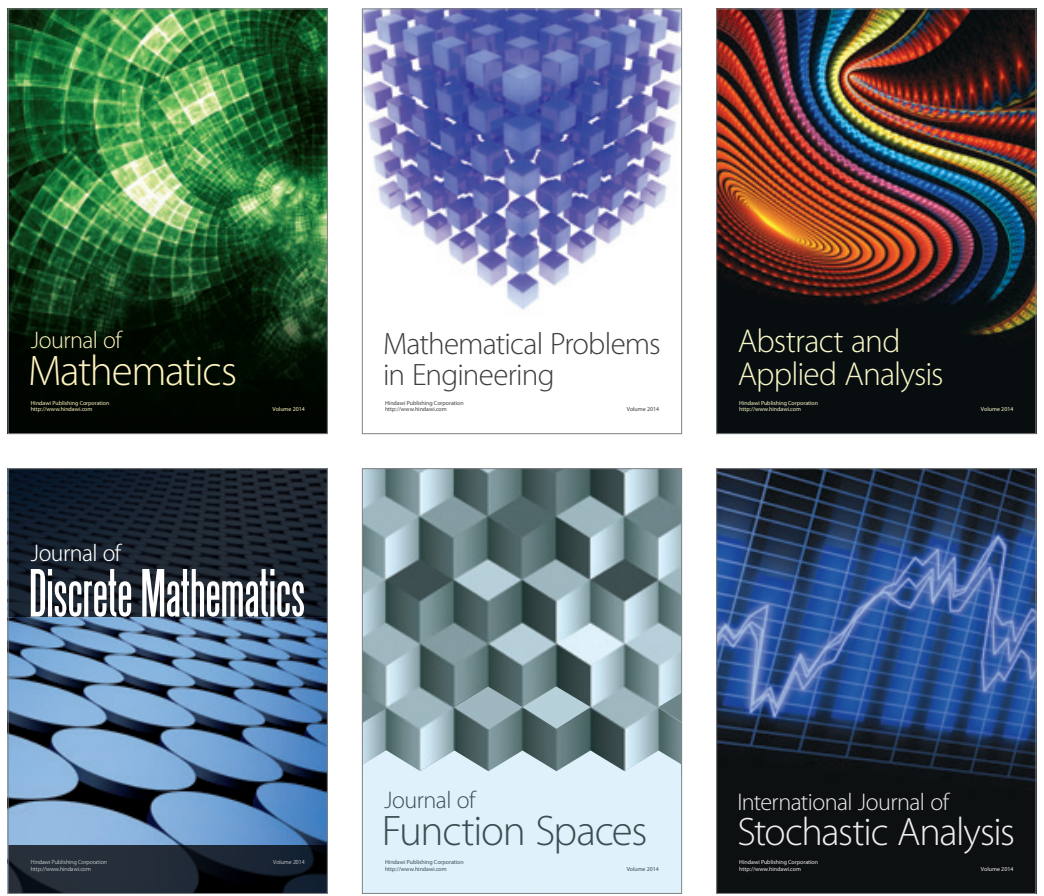

Journal of

Function Spaces

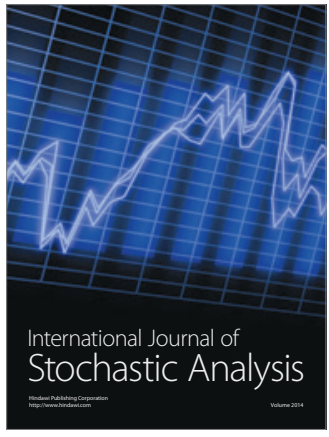

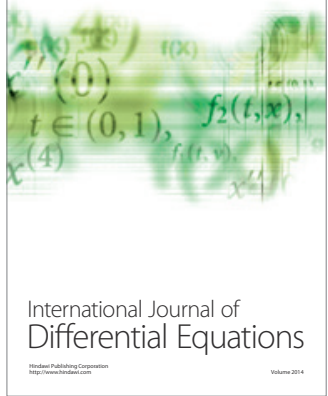
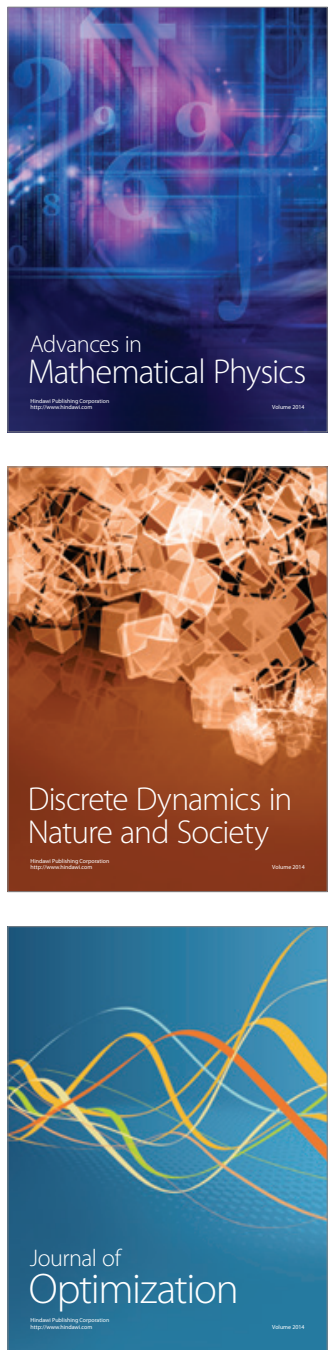